\title{
Regolith transport in the Dry Valleys of Antarctica
}

\author{
J. Putkonen, M. Rosales, N. Turpen, D. Morgan, G. Balco, and M. Donaldson \\ Department of Earth and Space Sciences, University of Washington, Seattle, WA 98195, USA
}

\begin{abstract}
The stability of ground surface and preservation of landforms that record past events and environments is of great importance as the geologic and climatic history is evaluated in the Dry Valleys of Antarctica. Currently little is known about the regolith transport that tends to eradicate and confound this record and regolith transport is itself an environmental indicator. Based on analyses of repeat photographs, soil traps, and pebble transport distances, it was found that there is a large spatial variation in topographic diffusivities at least in the annual basis and that counter intuitively the highest topographic diffusivities are found in the alpine valleys that are located farther inland from the coast where the lowest topographic diffusivities were recorded. An average topographic diffusivity for the Dry Valleys was determined to be $10^{-5}-10^{-4} \mathrm{~m}^{2} / \mathrm{yr}$. This average topographic diffusivity is surprisingly large, equaling or bordering the smallest values from elsewhere on Earth.
\end{abstract}

Citation: Putkonen, J., M. Rosales, N. Turpen, D. Morgan, G. Balco, and M. Donaldson (2007), Regolith transport in the Dry Valleys of Antarctica, in Antarctica: A Keystone in a Changing World - Online Proceedings of the 10th ISAES, edited by A. K. Cooper and C. R. Raymond et al., USGS Open-File Report 2007-1047, Short Research Paper 103, 5 p.; doi:10.3133/of2007-1047.srp103

\section{Introduction}

Numerous volcanic ash deposits many millions of years old are found at or near the soil surface in the Dry Valleys of Antarctica (e.g. Marchant et al., 1996) suggesting great stability of surfaces and preservation of unconsolidated regolith. On the other hand our current understanding of regolith degradation in other parts of the Earth has shown that unconsolidated deposits degrade at a relatively fast pace (Sharp and Birman, 1963; Burke and Birkeland, 1979; Hanks et al., 1984; Hallet and Putkonen, 1994; Putkonen and Swanson, 2003; Putkonen and O'Neal, 2006; Putkonen et al., 2007). Currently no direct or quantitative estimates of the regolith transport rates exist in the Dry Valleys. Here we attempt to use three independent techniques to measure directly the current and past regolith transport rates at three distinct and representative areas within the Dry Valleys.

\section{Field areas}

Although the typical mean annual air temperatures are $<-$ $20^{\circ} \mathrm{C}$ (Putkonen et al., 2003), running melt water is regularly observed in the lower valleys ( $\sim 200$ masl) and occasionally witnessed it in the alpine valleys $(>1000$ masl). The three distinct field areas where this study was conducted within the Dry Valleys are: 1) Arena and Beacon Valleys (1400 masl), 2) Koenig and upper Wright Valleys (1400 masl), and 3) lower Wright Valley (300 masl) (Figure 1).

\section{Field methods}

Three methods were used to determine directly the amount of regolith that is transported at the soil surface. Two of these methods resolve the sediment transport over a period of one year (1/2005-1/2006), and one method resolves over the entire lifespan of the deposit.

\section{Soil traps}

Soil traps are small wooden boxes (inside dimensions $25.5 \mathrm{~cm} \times 7.5 \mathrm{~cm} \times 4.5 \mathrm{~cm}$ ) that are open on the top. The boxes were buried on the slope so that the open top of the box was flush and even with the soil surface. As the regolith is transported downhill along the soil surface over the course of one year, it falls in and is trapped in the box. The complications rising from the field installation are explored in discussion section.

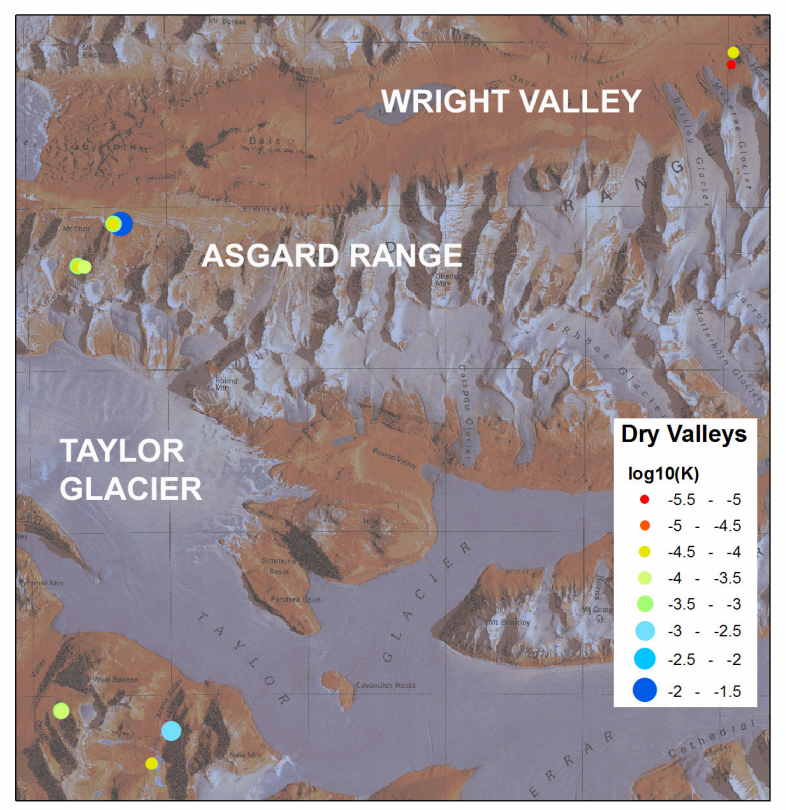

Figure 1. Map of the field area in the Dry Valleys of Antarctica, showing the study areas and topographic diffusivities ( $\kappa$ ) based on all regolith in the soil traps.

\section{Repeat photos of soil traps and undisturbed surfaces}

Since the installation of the soil traps will nonetheless disturb the surrounding ground surface to some degree, both the soil traps and undisturbed sites were photographed with a digital camera at the beginning and at the end of the observation period. The photographs were taken about $1.35 \mathrm{~m}$ above the soil surface covering approximately an area of $0.75 \times 0.75 \mathrm{~m}$. The smallest 
pebbles that were tracked and measured had an intermediate diameter of about $0.5 \mathrm{~cm}$.

\section{Boulder trails}

As boulders of distinct color or locally rare lithology weather on the hillslope a trail of pebbles is formed progressing downhill until thinning and vanishing. The source boulder dimensions, lithology, and local slope angle were recorded. A tape measure was laid straight through the highest fragment frequency that invariably followed the steepest slope downhill. All fragments within $0.1 \mathrm{~m}$ on each side of the tape measure were measured for mean dimension and distance from the source boulder. At certain fragment diameter the reliable detection of its lithology and source became unreliable and those fragments were ignored. The diameter of the smallest detectable fragment varied slightly between study sites and was on average $1.2 \mathrm{~cm}$, ranging from $<0.5-3.0 \mathrm{~cm}$. There was generally no ambiguity with the largest fragments whose average diameter was $11.6 \mathrm{~cm}$, ranging from $2.6-100.0 \mathrm{~cm}$.

\section{Data analyses}

The objective of all of our analyses is to determine the amount of regolith that travels along the soil surface in a given time period and on a given slope angle. With those data we can calculate the topographic diffusivity $\kappa\left(\mathrm{m}^{2} / \mathrm{yr}\right)$ that describes the efficiency of regolith transport (Culling, 1960; Carson and Kirkby, 1972; Hallet and Putkonen, 1994; Hanks, 2000; Putkonen and O'Neal, 2006; Putkonen et al., 2007). Topographic diffusivity has been determined for a wide range of climates and environments and allows a direct comparison of sites regardless of slope angle (Oehm and Hallet, 2005).

Our formal understanding of landform degradation follows a widely accepted mathematical formulation (Culling, 1960), which states that the mass transfer along the ground surface is equal to the local slope angle and a topographic diffusivity.

Topographic diffusivity is a key parameter that integrates the substrate and climate. Published values of topographic diffusivity range over three orders of magnitude $\left(10^{-1}-10^{-4} \mathrm{~m}^{2} / \mathrm{yr}\right)$ and no values currently exist for Dry Valleys, Antarctica (Hanks et al., 1984; Fernandes and Dietrich, 1997; Heimsath et al., 1997; Roering, 1999; Hanks, 2000; Oehm and Hallet, 2005).

The total regolith flux $\left(\mathrm{q}_{\mathrm{vol}, \mathrm{x}}\left[\mathrm{m}^{2} / \mathrm{yr}\right]\right)$ down the steepest local slope (x-direction), is proportional to the transport coefficient $\kappa\left(\mathrm{m}^{2} / \mathrm{yr}\right)$ and the corresponding slope inclination, $\partial \mathrm{y} / \partial \mathrm{x}$, where $\mathrm{y}$ is vertical dimension $(\mathrm{m})$ and $\mathrm{x}$ is horizontal dimension $(\mathrm{m})$ down the steepest slope. The simplest relation expressing the general increase in regolith flux with slope steepness is: $\mathrm{q}_{\mathrm{vol}, \mathrm{x}}=\kappa$ $\partial \mathrm{y} / \partial \mathrm{x}$ (eq. 1$)$.

At all field sites the local slopes were measured with a hand-held clinometer and are believed to be accurate to about $1.0^{\circ}$.

\section{Soil traps}

The volumetric regolith flux down the steepest local slope was measured by collecting all regolith that passes across an imaginary line that is level and follows the contour line at the soil surface. Here the width of the reference line is the inside width of the soil trap and the regolith volume is calculated by dividing the total mass that fell in the box by regolith density. The measurement period is 1 year.

Equation (1) can be readily solved for $\kappa$, by reorganizing and substituting tangent of the slope angle for $\mathrm{dy} / \mathrm{dx}$, and by dividing the $\mathrm{q}_{\mathrm{vol}, \mathrm{x}}$ by the average regolith density which in the area is approximately 1800 $\mathrm{kg} / \mathrm{m}^{3}$. The $\mathrm{q}_{\mathrm{vol}, \mathrm{x}}$ needs to be multiplied by the inside width of the soil trap $(0.255 \mathrm{~m})$ to account for the shorter than unit width of the measurement.

\section{Repeat photos of undisturbed ground surface and} soil traps

Determination of topographic diffusivity from repeat aerial photos requires several steps: 1) the photo pairs were first rectified in image processing software, 2) the scale was determined by measuring markers of known dimensions within photos, 3) the photo pair was overlaid in an image manipulation software, 4) all the exposed pebbles within a reference area were compared between the two images to determine whether the pebbles moved and how far. This technique allowed detection of pebbles down to about $0.5 \mathrm{~cm}$ diameter.

To compensate for the generally small number of pebbles that moved within a given frame an aerial average topographic diffusivity was calculated instead of determining only the volume of pebbles that crossed a randomly placed horizontal contour line.

To calculate the reference area average topographic diffusivity, a pebble that had moved between the taking of the two photographs was measured for the intermediate axes length. The approximate volume of the pebble was calculated by cubing the length of the intermediate axis. The straight distance between the pebble initial center of the mass and the final center of the mass in $\mathrm{cm}$ was measured.

The total volumetric regolith flux in $\mathrm{x}$-direction $\left(\mathrm{q}_{\mathrm{vol}, \mathrm{x}, \text { mean }}\right)$ is calculated:

$$
q_{\text {vol }, x, \text { mean }}=\frac{\sum_{1}^{n} \frac{V_{n} \cdot d_{n}}{\Delta t}}{A}
$$

where $\mathrm{n}$ is the number of individual pebbles that moved, $V_{n}$ is the volume of a given pebble $\left(\mathrm{m}^{3}\right), \mathrm{d}_{\mathrm{n}}$ is the distance a given pebble moved $(\mathrm{m}), \Delta \mathrm{t}$ is the time difference between initial and final measurements (years), and $\mathrm{A}$ is the reference area where the pebbles have been measured $\left(\mathrm{m}^{2}\right)$. The topographic diffusivity is calculated 
by substituting $\mathrm{q}_{\mathrm{vol}, \mathrm{x}}$ in equation 1 by $\mathrm{q}_{\mathrm{vol}, \mathrm{x}, \text { mean }}$ and solving for $\kappa$.

\section{Long term transport rate}

The trail of rock fragments of distinct lithology that originate from an obvious source boulder on a hillslope indicates the downhill transport of surficial regolith. To calculate the corresponding estimate of the topographic diffusivity all fragments are measured for volume and distance from the source boulder within a $0.1 \mathrm{~m}$ wide swath along the highest concentration of fragments and the transport rate is calculated by using equations 1 and 2 .

It is expected that the fragments continue to weather while they are in transport and eventually become too small for visual detection. Therefore as some of the fragments are lost through attrition this method is assumed to provide a minimum estimate of topographic diffusivity. It is also reasonable to assume that many more rock fragments of comparable size are transported in the same study plot but since they are not related to the source boulder they are not counted which further decreases the value of computed topographic diffusivity.

The time that is entered in equation 2 is the time since the deposition of the regolith and in most cases would be the time since the last warm based glaciation receded from the site. Many of the drifts in the Dry Valleys have been dated by volcanic ashes and cosmogenic isotopes which place the surfaces typically within a range of 1-13 Ma (e.g. Brook et al., 1991; Brown et al., 1991; Marchant et al., 1996). Given the uncertainties in the dating control, difficulty in locating exact boundaries between mapped units in the field, and the fact that many boulder trail measurements come from units that are classified as undifferentiated colluvium in published maps we solved the topographic diffusivities for both 1 and $13 \mathrm{Ma}$ exposure time. The results are reported as a range of diffusivities based on the same boulder trail data and assumed $1 \mathrm{Ma}$ exposure and $13 \mathrm{Ma}$ exposure to reflect the uncertainty.

\section{Results}

All the measurements of regolith transport were converted into topographic diffusivities to allow comparison across varying slope angles within the Dry Valleys, and climates and environments elsewhere on Earth (see equation 1 for definition of topographic diffusivity).

Figure 2 shows mean topographic diffusivities for five separate categories which are all measured in the Dry Valleys. The categories are: 1) boulder trails, 2) repeat photos, 3) soil trap repeat photos generally follow analytical procedures for repeat photos with the exception that an attempt was made to discard regolith movement directly caused by the installation of the traps or within the disturbed ground close to the box, 4) soil traps D>5.6 $\mathrm{mm}$; the regolith that was trapped in the box was sieved and only the fraction that passed through the $5.6 \mathrm{~mm}$ sieve is included in the calculations, 5) soil traps all grain sizes; all the regolith that was trapped in boxes is included in these calculations.

The spatial variation in topographic diffusivities that are solved from soil traps including all grain sizes (Figure 1) shows that the lowest $\kappa$ values are found in lower Wright Valley and the highest values are found at high elevations and inland in the alpine valleys. This suggests broadly less regolith transport near the coast than in the alpine valleys within the study period.

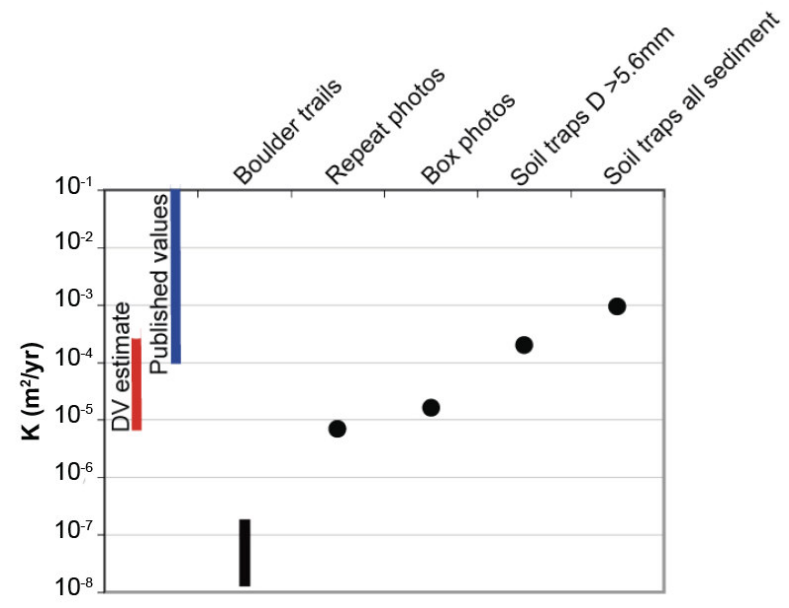

Figure 2. Mean topographic diffusivities for all methods. Blue vertical bar shows the range of published topographic diffusivities on Earth. Red vertical bar (DV estimate) shows the estimated range of mean topographic diffusivity in the Dry Valleys of Antarctica based on this research.

\section{Discussion}

None of the methods employed in this study alone are perfect for accurate determination of either short or long term sediment transport. However, when the systematical biases in individual methods are taken into account, these methods provide collectively robust means to bracket current sediment transport rates in the area. The minimum limiting values are provided by repeat photography which misses the movement of the finest sediments (diameter $<0.5 \mathrm{~cm}$ ) and therefore it can be concluded that the average topographic diffusivity has to be $>6.9 \times 10^{-6}$ $\mathrm{m}^{2} / \mathrm{yr}$. On the other hand the installation of soil traps inevitably disturbs the surrounding soil which becomes more mobile and artificially increases the amount of trapped sediment. Therefore the natural topographic diffusivity has to be $<9.4 \times 10^{-4} \mathrm{~m}^{2} / \mathrm{yr}$. Moreover, as the desert pavement, which is pervasive in the field area, is disturbed by the installation of the boxes it is likely that a disproportionally large fraction of fine sediments are mobilized. Therefore we suggest that the larger grain size fraction alone (soil traps $\mathrm{D}>5.6 \mathrm{~mm}$ ) may more closely establish a maximum limiting transport rate. The corresponding maximum limiting topographic diffusivity in the area would be $<2.0 \times 10^{-4} \mathrm{~m}^{2} / \mathrm{yr}$. 
Given all the uncertainties and relatively small sample size we suggest rounding the numbers to provide an order of magnitude estimate of the current topographic diffusivity in the dry Valleys, which is $10^{-5}-10^{-4} \mathrm{~m}^{2} / \mathrm{yr}$. At the lower end of this range the topographic diffusivity is about an order of magnitude smaller than the smallest recorded values elsewhere on the Earth, however, on the upper end the topographic diffusivity is equal to smallest reported values elsewhere on Earth. This suggests that the regolith transport rates in cold deserts may not differ significantly from warm deserts such as are found in Israel and Nevada, USA (Enzel et al., 1996; Hanks, 2000).

As is apparent from Table 1 and Figure 2, the topographic diffusivity that is solved from boulder trails and that applies for a much longer time period is 2-4 orders of magnitude smaller than the suggested current topographic diffusivity. This may simply reflect a recent significant acceleration of sediment transport rate in this area. However, it is believed that even though the method provides a limiting lower estimate of the long term topographic diffusivity it also significantly underestimates the true value. The reasons for this assertion are three fold: 1) after the initial deposition of the source boulder in the hillslope there is some lag time before the first rock fragments are deposited on the base of the boulder, 2) the rock fragments brake further while they are transported downhill, eventually becoming too small for detection, 3) much more rock fragments and soil is transported in the study plot but because they are not of contrasting color or lithology their origin remains unknown.

We suggest that because the typical surface exposure times in the Dry Valleys are in the order of millions of years the smallest recorded terrestrial topographic diffusivities that are reported here still render surface processes important for landscape evolution and disturbance of surfaces.

The spatial pattern of topographic diffusivities that are based on soil traps with all trapped regolith is shown in Figure 1. It is counterintuitive that the lowest diffusivities are found closest to the coast and at low elevation, as these areas ostensibly appear more geomorphologically active due to observed gravel dunes and consistently running streams and melt water rivulets. The highest individual value of topographic diffusivity is recorded at a site where snow melt was feeding a silty deposit that completely filled the trap and collected in a heap that over-filled the box. Yet only a few hundred meters to the west another trap in apparently similar substrate collected only a dusting of silt. This goes to show that there exists a large spatial variation in the regolith transport rates at least in the annual time scale. The higher than expected topographic diffusivity suggests that the surfaces in Dry Valleys are currently renewed by erosion and deposition.

\section{Conclusions}

The stability of ground surfaces and preservation of deposits that record past events and environments is of great importance as the geologic and climatic history is evaluated in the Dry Valleys of Antarctica. The presence of many ancient volcanic ashes at or near soil surfaces suggests great preservation of the sedimentary deposits in the Dry Valleys and vanishingly small sediment transport rates. Elsewhere on Earth sediment erosion, transportation, and deposition tend to eradicate and rework landforms and deposits within few 100's of ka, but since no direct measurements exists of the regolith transportation rates in the Dry Valleys the apparent preservation can not be quantitatively and independently assessed.

Based on analyses of repeat photographs, soil traps, and rock fragment transport distances in the Dry Valleys a sediment transport coefficient (topographic diffusivity) was calculated. The topographic diffusivity relates the sediment transport rate per unit width of the slope to the local slope angle. Instead of comparing the actual volumes of sediment transport on various slopes which largely reflects the steepness of the given slope, the topographic diffusivity yields the sediment transport rate normalized to the local slope. Therefore the expectation is that the topographic diffusivity is a constant within a given field area and typically is insensitive to the varying slope angles.

Table 1. Mean, maximum, minimum, standard deviation and number of data points (n) for all calculated categories of topographic diffusivity.

\begin{tabular}{|l|c|c|c|c|c|}
\hline & Mean $\left(\mathrm{m}^{2} / \mathrm{yr}\right)$ & $\operatorname{Max}\left(\mathrm{m}^{2} / \mathrm{yr}\right)$ & $\operatorname{Min}\left(\mathrm{m}^{2} / \mathrm{yr}\right)$ & $\operatorname{Std}\left(\mathrm{m}^{2} / \mathrm{yr}\right)$ & $\mathrm{n}$ \\
\hline Boulder trails, 1 Ma exposure & $1.5 \times 10^{-7}$ & $3.4 \times 10^{-6}$ & $7.1 \times 10^{-11}$ & & 68 \\
\hline Boulder trails, 13 Ma exposure & $1.2 \times 10^{-8}$ & $2.6 \times 10^{-7}$ & $5.4 \times 10^{-12}$ & & 68 \\
\hline Repeat photos & $6.9 \times 10^{-6}$ & $1.9 \times 10^{-5}$ & $8.3 \times 10^{-7}$ & $6.6 \times 10^{-6}$ & 7 \\
\hline Box photos & $1.6 \times 10^{-5}$ & $4.9 \times 10^{-5}$ & $1.5 \times 10^{-6}$ & $1.9 \times 10^{-5}$ & 5 \\
\hline Soil traps D $>5.6 \mathrm{~mm}$ & $2.0 \times 10^{-4}$ & $3.0 \times 10^{-3}$ & $5.4 \times 10^{-6}$ & $8.0 \times 10^{-4}$ & 14 \\
\hline Soil traps all grain sizes & $9.4 \times 10^{-4}$ & $1.2 \times 10^{-2}$ & $6.4 \times 10^{-6}$ & $2.8 \times 10^{-3}$ & 19 \\
\hline
\end{tabular}


The various analyses in this study were used to collectively bracket an order of magnitude estimate of the current average topographic diffusivity for the Dry Valleys that is $10^{-5}-10^{-4} \mathrm{~m}^{2} / \mathrm{yr}$. This topographic diffusivity equals or is less than what has previously been reported elsewhere on Earth (Oehm and Hallet, 2005). The topographic diffusivity that is reported here applies strictly speaking only to those field sites during the study period $1 / 2005-1 / 2006$.

It was found that there is a large spatial variation in topographic diffusivities in the annual basis in the Dry Valleys. The highest topographic diffusivities are found in the alpine valleys that are located farther inland from the coast. The diffusivities near the coast were the lowest.

The boulder trails yield a limiting minimum estimate of long term mean topographic diffusivity that is $10^{-8}-10^{-7}$ $\mathrm{m}^{2} / \mathrm{yr}$. Although the boulder trails are valuable markers of general geomorphological activity and sediment transport on the hillslopes, it is believed that the analyses based on them significantly underestimate the true long term mean topographic diffusivity in the area.

Acknowledgement. This research was supported by U.S. National Science Foundation grant OPP-338224, NASA Summer Undergraduate Research Program, and Quaternary Research Center University of Washington. The enthusiastic help of students J. Connolly, K. Craig, and B. O'Donnell helped us accomplish optimistic goals in the field. We are thankful for H. Greenberg for producing Figure 1 .

\section{References}

Brook, E. J., Kurz, M. D., Ackert, R. A., and Denton, G. H. (1991). Surface-exposure chronology of Antarctic glacial deposits using insitu produced cosmogenic 3He. Eos, Transactions, American Geophysical Union 72, 309.

Brown, E. T., Edmond, J. M., Raisbeck, G. M., Yiou, F., Kurz, M. D., and Brook, E. J. (1991). Examination of surface exposure ages of Antarctic moraines using in situ produced ${ }^{10} \mathrm{Be}$ and ${ }^{26} \mathrm{Al}$. Geochimica et Cosmochimica Acta 55, 2269-2283.

Burke, R. M., and Birkeland, P. W. (1979). Reevaluation of multiparameter relative dating techniques and their application to the glacial sequence along the eastern escarpment of the Sierra Nevada, California. Quaternary Research 11, 21-51.

Carson, M. A., and Kirkby, M. J. (1972). "Hillslope Form and Process." Cambridge University Press, England.

Culling, W. E. H. (1960). Analytical theory of erosion. Journal of Geology 68, 336-344.
Enzel, Y., Amit, R., Porat, N., Zilberman, E., and Harrison, B. J. (1996). Estimating the ages of fault scarps in the Arava, Israel. Tectonophysics 253, 305-317.

Fernandes, N. F., and Dietrich, W. E. (1997). Hillslope evolution by diffusive processes: The timescale for equilibrium adjustments. Water Resources Research 33, 1307-1318.

Hallet, B., and Putkonen, J. (1994). Surface dating of dynamic landforms; young boulders on aging moraines. Science 265, 937-940.

Hanks, T. C. (2000). The age of scarplike landforms from diffusionequation analysis. In "Quaternary Geochronology Methods and Applications." (J. S. Noller, J. M. Sowers, and W. R. Lettis, Eds.), pp. 582. AGU Reference Shelf. American Geophysical Union, Washington, DC.

Hanks, T. C., Bucknam, R. C., Lajoie, K. R., and Wallace, R. E. (1984). Modification of wave-cut and faulting-controlled landforms. Journal of Geophysical.Research 89, 5771-5790.

Heimsath, A. M., Dietrich, W. E., Nishiizumi, K., and Finkel, R. C. (1997). The soil production function and landscape equilibrium. Nature 388.

Marchant, D. R., Denton, G. H., Swisher, C. C. I., and Potter, N. J. (1996). Late Cenozoic Antarctic paleoclimate reconstructed from volcanic ashes in the dry valleys region of southern Victoria Land. Geological Society of America Bulletin 108, 181-194.

Oehm, B., and Hallet, B. (2005). Rates of soil creep, worldwide: weak climatic controls and potential feedback. Zeitchrift fur Geomorphologie 49, 353-372.

Putkonen, J., Balco, G., and Morgan, D. (In Review). Slow regolith degradation determined by cosmogenic-nuclide concentrations in Arena Valley, Antarctica. Quaternary Research.

Putkonen, J., Connolly, J., and Orloff, T. (2007). Landscape evolution degrades the geologic signature of past glaciations. Geomorphology.

Putkonen, J., and O'Neal, M. A. (2006). Degradation of unconsolidated Quaternary landforms in the western North America. Geomorphology 75, 408-419.

Putkonen, J., Sletten, R. S., and Hallet, B. (2003). Atmosphere/ice energy exchange through thin debris cover in Beacon Valley, Antarctica. In "Eighth international conference on Permafrost, Zurich, Switzerland, July 21-25, 2003." (M. Phillips, S. M. Springman, and L. U. Arenson, Eds.), pp. 913-915. Swiss Federal Institute for Snow and Avalanche Research, Davos, Switzerland (CHE), Zurich, Switzerland.

Putkonen, J., and Swanson, T. (2003). Accuracy of cosmogenic ages for moraines. Quaternary Research 59, 255-261.

Roering, J. J. (1999). Evidence for non-linear, diffusive sediment transport on hillslopes and implications for landscape morphology. Water Resources Research 35, 853-870.

Sharp, R. P., and Birman, J. H. (1963). Additions to classical sequence of Pleistocene glaciations, Sierra Nevada, California. Geological Society of America Bulletin 74, 1079-1086. 